\title{
Long-term macrolide therapy in chronic obstructive pulmonary disease
}

\author{
Ganapathi lyer Parameswaran MBBS, Sanjay Sethi MD
}

See also commentary on page 1127 and at www.cmaj.ca/lookup/doi/10.1503/cmaj.140572

Competing interests: None declared.

This article has been peer reviewed.

\section{Correspondence to:}

Sanjay Sethi, ssethi@

buffalo.edu

CMAJ 2014. DOI:10.1503 /cmaj.121573 $\sqrt{4}$ xacerbations of chronic obstructive pulmonary disease (COPD) are characterized by worsening respiratory symptoms, which are almost always accompanied by an increase in airway inflammation. ${ }^{1-3}$ The majority of these exacerbations are caused by microbial infection. ${ }^{4}$ By current estimates, about $50 \%$ of exacerbations are caused by bacteria, either alone or in combination with viruses. ${ }^{4}$ Before 1970 , multiple attempts were made to test the hypothesis that prophylactic antibiotics can reduce the frequency of COPD exacerbations. Unfortunately, the trials were small, with differing methods and antibiotic choices. Most used antibiotics that would likely not be effective today, given changes in antibiotic susceptibilities of bacterial pathogens. A systematic review of these trials did show a small reduction in the frequency of exacerbations (odds ratio [OR] 0.91, 95\% confidence interval [CI] 0.84-0.99). ${ }^{5}$ However, because the effect was modest and because of methodologic limitations and concerns about antibiotic resistance, these results cannot be applied in the present-day care of patients with COPD.

A resurgence of interest in the use of prophylactic antibiotics in COPD has emerged over the past decade, with an emphasis on the use of macrolides. It might be assumed that the antimicrobial properties of macrolides were the premise for studying whether these drugs can be used to prevent exacerbations, given that they

are used to treat exacerbations on this basis. In fact, this use of macrolides has been based more on their potential anti-inflammatory and immunoregulatory effects, which have been shown in both in vitro experimental models and other inflammatory lung diseases. In this paper, we review the evidence for benefit and potential harms of long-term prophylactic macrolide therapy in reducing COPD exacerbations. This evidence is derived (using the search strategy outlined in Box 1) primarily from a few randomized trials, dominated by one large recent trial.

\section{What biological actions of macrolides are relevant to COPD?}

It is likely that the antibacterial effects of macrolides contribute to their effects on exacerbations in COPD. Patients with COPD who have colonization by pathogenic bacteria have higher levels of airway inflammation than those without such colonization. ${ }^{6}$ Hence, eradication or suppression of chronic bacterial colonization by macrolides could reduce infection-related airway inflammation, make the airway milieu less hospitable to infection with new strains of bacteria and viruses, and thus reduce the likelihood of exacerbation.

The four major bacterial pathogens involved in exacerbations of COPD are nontypeable Haemophilus influenzae, Moraxella catarrhalis, Streptococcus pneumoniae and Pseudomonas aeruginosa. ${ }^{4}$ Almost all strains of $H$. influenzae and $M$. catarrhalis are susceptible to clarithromycin and azithromycin, ${ }^{7}$ as are the majority of strains of $S$. pneumoniae. ${ }^{8}$

$P$. aeruginosa is not clinically susceptible to macrolides. However, macrolides have indirect activity against $P$. aeruginosa through suppression of virulence factors, which may contribute to their beneficial effects in reducing exacerbations. ${ }^{9}$ Macrolides suppress the synthesis of elastase, lecithinase and pyocyanin, and they alter 
the structure of Pseudomonas endotoxin (lipopolysaccharide). The motility of $P$. aeruginosa is reduced by a decrease in flagellin production, and biofilm formation is inhibited through interference with the production of alginate and quorum signalling. ${ }^{9,10}$

However, it is probable that immunomodulatory effects are responsible for at least a part of the actions of macrolides in COPD. In vitro cell culture and animal models have shown that macrolides possess potent anti-inflammatory and immunomodulatory properties (Box 2). ${ }^{11,12}$ Relative to alveolar macrophages from healthy controls, those from patients with COPD have decreased ability to phagocytose apoptotic cells (efferocytosis) ${ }^{14}$ and pathogenic bacteria. ${ }^{15}$ Azithromycin reverses this deficit in efferocyto$\mathrm{sis}^{14}$ and improves the ability of macrophages from patients with COPD to phagocytose bacteria. ${ }^{16}$ Furthermore, macrolides were successful in preventing exacerbations and improving lung function in cystic fibrosis ${ }^{17,18}$ and improving survival in diffuse panbronchiolitis. ${ }^{19}$ In these two airway diseases, the major pathogen is $P$. aerugi$n o s a$, against which macrolides are decidedly ineffective in conventional antimicrobial terms. In addition, two trials of erythromycin prophylaxis in COPD used doses lower than required for antimicrobial effects, but the drug was nevertheless beneficial. ${ }^{20,21}$ However, measurements of pro-inflammatory cytokines in patients with COPD enrolled in macrolide treatment trials have yielded conflicting results. Therefore, there is still no clear evidence that the benefits of macrolides in COPD are related to these immunomodulatory effects.

Gastroesophageal reflux has been shown to be a risk factor for increased frequency of exacerbation. ${ }^{22}$ Macrolides improve gastric emptying and reduce gastroesophageal reflux,,$^{23,24}$ and it is tempting to speculate that these effects contribute to a reduction in COPD exacerbations.

\section{What are the potential benefits of long-term macrolide therapy in COPD?}

Four randomized trials have compared a macrolide with placebo for preventing COPD exacerbations (Table 1). The first three recruited small numbers of patients and thus had low power to detect meaningful clinical benefits and risks. ${ }^{20,21,25}$ Despite this limitation, two of the trials reported significant reduction of exacerbations in the macrolide group. ${ }^{20,21}$

More recently, Albert and colleagues ${ }^{26}$ conducted a multicentre randomized controlled trial comparing azithromycin $250 \mathrm{mg}$ daily with placebo for 12 months in 1142 patients with COPD who were considered at high risk for exacerbation (defined as use of systemic steroids within the previous year, use of continuous supplemental oxygen or history of hospital admission for exacerbation in the preceding 12 months). Excluded were patients with a diagnosis of asthma, resting tachycardia, prolonged corrected QT (QTc) interval on electrocardiography, medications known to increase the QTc interval or hearing impediment. Azithromycin prolonged the median time to first exacerbation, the study's primary end point (266 v. 174 days, $p$ $<0.001$ ) and reduced the rate of exacerbations (hazard ratio [HR] $0.73,95 \%$ CI $0.63-0.84$ ). Quality of life at the end of one year, as assessed by the St. George's Respiratory Questionnaire, showed significantly greater improvement with azithromycin $(2.8 \pm 12.8$ v. $0.6 \pm$ 11.4 units; $p=0.004$ ), but the mean change was less than the minimal clinically important difference for this measure (4 units). Unscheduled office visits were significantly fewer in the

\section{Box 1: Evidence used in this review}

We searched the MEDLINE database (for the period 2002 to 2013) using the following medical subject headings (MeSH): "macrolides" or "azithromycin" or "erythromycin" or "clarithromycin" and "lung disease." We limited the search to English-language articles involving human subjects for which an abstract was available. Of 496 articles initially identified, 120 were found to be relevant, of which 34 are included in this article.

Box 2: Anti-inflammatory and immunomodulatory effects of macrolides ${ }^{11,12}$

Effects of macrolides on neutrophils:

- Accumulate in leukocytes at levels higher than in serum

- Inhibit neutrophil adhesion and migration to sites of inflammation

- Decrease the oxidative burst

Effects of macrolides on alveolar macrophages:

- Inhibit activation of transcription factor NF- $\kappa \mathrm{B}$, which controls the expression of many inflammatory cytokines, chemokines, immune receptors and cell-surface adhesion molecules

- Decrease production of major cytokines involved in initiating the inflammatory response (TNF- $\alpha$ and IL-1)

Effects of macrolides on airway epithelial cells:

- Reduce activation of transcription factors AP-1 (transcription factor involved in activation of genes coding for cytokines involved in inflammatory response) and NF-KB

- Decrease production of IL-6 and IL-8 in response to Haemophilus influenzae, thus reducing neutrophil chemotaxis to the site of infection

- Decrease secretion and viscosity of mucin

- Improve frequency of ciliary beating

- Promote epithelial integrity and transepithelial resistance by changing processing of tight junction proteins (azithromycin only) ${ }^{13}$

Note: AP-1 = activator protein-1, IL = interleukin, NF- $\mathrm{B}$ = nuclear factor kappa-light-chainenhancer of activated B cells, TNF- $\alpha=$ tumour necrosis factor $\alpha$. 
azithromycin group (HR 0.85, 95\% CI 0.74 0.98 ), but rates of hospital admission did not differ (HR 0.94, 95\% CI 0.76-1.15).

\section{What are the potential harms of long-term macrolide therapy in COPD?}

Macrolides were generally well tolerated in the four studies cited above. Albert and colleagues ${ }^{26}$ observed no differences in rates of death or adherence with study medications. More of the patients taking azithromycin had a significant decrease in audiometry scores than was the case among patients taking placebo $(25 \%$ v. $20 \%, p=$ 0.004; number needed to harm 20). Hearing loss, both reversible and irreversible, has been reported as an adverse effect of macrolides. ${ }^{27,28}$ The possibility that the frequency and severity of this adverse event might increase with even longer courses of azithromycin is a concern.

Because macrolides increase the QTc interval and also increase the chance of torsades de pointes, another concern relates to adverse cardiovascular events and increased mortality, a possibility raised in a recent publication by Ray and colleagues. ${ }^{29}$ Using the Tennessee Medicaid database, these investigators compared patients who took azithromycin for five days (about
380000 prescriptions) with a propensity-matched sample of about 1.4 million patients who took no antibiotics. Patients taking azithromycin had a greater risk for cardiovascular-related death (HR $2.88,95 \%$ CI 1.79-4.63) and death from any cause (HR 1.85, 95\% CI 1.25-2.75) than patients taking no antibiotics. This increase in risk was most pronounced among patients who were at high risk of cardiovascular disease. Given the observational study design, uncontrolled confounding factors such as sex and pre-existing cardiac risks might have influenced the results.

Divergent findings were subsequently published in another retrospective cohort study involving patients in the Danish national health registry. ${ }^{30}$ More than one million health visits with prescription of azithromycin were matched (by propensity scores, to control for baseline differences) with a similar number of visits without prescription of antibiotics and with about seven million visits with prescription of penicillin $\mathrm{V}$. Although there were more deaths from cardiovascular causes in the azithromycin group than in the nonantibiotic group (rate ratio $2.85,95 \%$ CI 1.13-7.24), this rate was not significantly different from the rate in the penicillin $\mathrm{V}$ group (rate ratio $0.93,95 \%$ CI $0.56-1.55$ ). This result suggests that the difference in cardiovascular deaths was related to other characteristics, such as comorbidities, among the patients receiving

Table 1: Summary of randomized trials of prophylactic macrolide therapy in COPD

\begin{tabular}{|c|c|c|c|c|}
\hline Reference & Design & No. of patients & Intervention & Results \\
\hline Suzuki et al. ${ }^{21}$ & $\begin{array}{l}\text { Prospective, } \\
\text { open-label, } \\
\text { randomized }\end{array}$ & $\begin{array}{l}\text { 109, any severity } \\
\text { of COPD }\end{array}$ & $\begin{array}{l}\text { Erythromycin } \\
200-400 \text { mg daily } \\
\text { v. riboflavin for } \\
12 \text { mo }\end{array}$ & $\begin{array}{l}\text { Significant reduction in common colds }(1.24 \pm \\
0.07 \text { v. } 4.54 \pm 0.02 \text { for erythromycin and riboflavin } \\
\text { groups; } p<0.001) \text { and exacerbations (RR for } \\
\text { control group } 4.71,95 \% \mathrm{Cl} 1.53-14.5 \text { ) }\end{array}$ \\
\hline $\begin{array}{l}\text { Banerjee et } \\
\text { al. }{ }^{25}\end{array}$ & $\begin{array}{l}\text { Prospective, } \\
\text { double-blind, } \\
\text { randomized }\end{array}$ & $\begin{array}{l}67, \text { moderate to } \\
\text { severe COPD }\end{array}$ & $\begin{array}{l}\text { Clarithromycin } \\
500 \mathrm{mg} \text { daily } \mathrm{v} \text {. } \\
\text { placebo for } 3 \mathrm{mo}\end{array}$ & $\begin{array}{l}\text { Significant improvement in symptom domain of } \\
\text { SGRQ (mean difference } 10.2,95 \% \mathrm{Cl} 1.6-18.7) ; \text { no } \\
\text { significant difference in SGRQ score* or } \\
\text { exacerbation frequency ( } 5 \text { v. } 3 \text { in clarithromycin } \\
\text { and placebo groups; } p=0.2 \text { ). }\end{array}$ \\
\hline $\begin{array}{l}\text { Seemungal et } \\
\text { al. }^{20}\end{array}$ & $\begin{array}{l}\text { Prospective, } \\
\text { double-blind, } \\
\text { randomized }\end{array}$ & $\begin{array}{l}109, \text { moderate to } \\
\text { severe COPD }\end{array}$ & $\begin{array}{l}\text { Erythromycin } \\
250 \mathrm{mg} \text { daily } \mathrm{v} \text {. } \\
\text { placebo for } 12 \mathrm{mo}\end{array}$ & $\begin{array}{l}\text { Significant reduction in exacerbation frequency } \\
\text { (rate ratio } 0.648 \text { [ } 95 \% \mathrm{Cl} 0.489-0.859] \text { for } \\
\text { erythromycin v. control group); no difference in } \\
\text { sputum markers of inflammation (IL-6, IL-8, } \\
\text { myeloperoxidase) }\end{array}$ \\
\hline Albert et al. ${ }^{26}$ & $\begin{array}{l}\text { Prospective, } \\
\text { double-blind, } \\
\text { randomized }\end{array}$ & $\begin{array}{l}\text { 1142, moderate to } \\
\text { very severe COPD } \\
\text { (GOLD stages II-IV) }\end{array}$ & $\begin{array}{l}\text { Azithromycin } \\
250 \mathrm{mg} \text { daily } \mathrm{v} \text {. } \\
\text { placebo for } 12 \mathrm{mo}\end{array}$ & $\begin{array}{l}\text { Significant reduction in exacerbation frequency } \\
\text { (HR } 0.73,95 \% \mathrm{Cl} 0.63-0.84) \text {; increase in median } \\
\text { time to next exacerbation ( } 266 \mathrm{v} .174 \mathrm{~d} \text { for } \\
\text { azithromycin and placebo groups; } p<0.001 \text { ); } \\
\text { significant improvement in SGRQ }(2.8 \pm 12.8 \mathrm{v} \text {. } \\
0.6 \pm 11.4 \text { units, } p=0.004 \text { ); reduction in } \\
\text { unscheduled office visits (HR } 0.85,95 \% \mathrm{Cl} \\
0.74-0.98 \text { ); no significant difference in rates of } \\
\text { hospital admission (HR } 0.94,95 \% \mathrm{Cl} 0.76-1.15 \text { ) }\end{array}$ \\
\hline
\end{tabular}


antibiotics, rather than a specific risk associated with azithromycin.

Finally, Albert and colleagues ${ }^{26}$ observed no difference in cardiovascular adverse events or mortality, in spite of the considerable exposure to macrolides in their study. This result may be related to careful patient selection, with exclusion of patients who had prolonged QTc (and those taking other medications known to prolong QTc), as well as to differences in design and sample size. The sample size in the randomized study by Albert and colleagues ${ }^{26}$ was much smaller than sample sizes in the large observational studies described above, ${ }^{29,30}$ and smaller sample size reduces the power to detect infrequent events.

In view of these conflicting findings, caution should be exercised in the use of azithromycin for patients with known cardiac disease (see Box 3 ). We recommend performing baseline electrocardiography to ensure that the QTc interval is not prolonged, as well as baseline audiometry. Periodic audiometric evaluations are also prudent while the patient is receiving treatment. For example, in the study by Albert and colleagues, ${ }^{26}$ audiometric evaluations were performed at the start of treatment, at 3 months and at 12 months.

\section{Does long-term macrolide therapy contribute to antibiotic resistance?}

In patients with COPD, intermittent use of macrolides to treat exacerbations has been associated with isolation of macrolide-resistant strains of S. pneumoniae from sputum..$^{31}$ Albert and colleague ${ }^{26}$ observed an increase in the incidence of macrolide-resistant nasopharyngeal bacteria among patients receiving azithromycin. In that study, nasopharyngeal swabs were used to evaluate respiratory colonization, and swabs were obtained for about $85 \%$ of patients. The rates of colonization by Staphylococcus aureus, $H$. influenzae, M. catarrhalis and S. pneumoniae did not differ between the groups at the start of the study. By the end of the study period, significantly fewer patients in the azithromycin group had colonization with the same pathogens. However, among patients in the azithromycin group with occurrence of colonization during the study period, the chance of azithromycin resistance in the pathogens isolated was significantly higher $(p<0.001)$. In other words, when patients on long-term azithromycin acquired new nasopharyngeal bacteria, those bacterial strains were more likely to be resistant to azithromycin.

Previous epidemiologic studies have clearly shown an association between use of macrolides in the community and prevalence of macrolideresistant S. pneumoniae. From 1993 to 1999, macrolide prescriptions increased by $13 \%$ in the United States, with an especially steep increase (by 320\%) among children under five years of age. The rate of macrolide resistance in S. pneumoniae isolates increased from $10.6 \%$ to $20.4 \%$ over the same period. ${ }^{32}$ In Israel, isolation of macrolide-resistant $S$. pneumoniae among children increased during the winter months, the same season when macrolide use increased among these patients. ${ }^{33}$ In 2005-2006, 35.3\% of $S$. pneumoniae in the US was resistant to macrolides. ${ }^{8}$ Prolonged macrolide use in a large group of patients with COPD could lead to loss of a useful antibiotic class for treatment of acute respiratory infections, not only among the patients who receive the treatment but also in the wider community.

Patients who need antibiotics for a respiratory tract infection while they are receiving macrolide prophylaxis (including exacerbation, pneumonia or sinusitis) would be best treated with a nonmacrolide antibiotic, because of concerns about infection with a macrolide-resistant bacterial strain.

\section{Unanswered questions}

Whether intermittent azithromycin prophylaxis (250 mg three times a week) would be as effective as daily dosing in preventing exacerbations is unknown. The intermittent regimen is effective in cystic fibrosis ${ }^{34}$ and is our preferred starting regimen, with transition to daily dosing if intermittent dosing appears ineffective.

Although generally safe and effective, macrolides have the potential for adverse effects and

\section{Box 3: Selection criteria for azithromycin prophylactic therapy} in COPD ${ }^{20,26}$

Patients likely to benefit from azithromycin prophylaxis:

- Moderate to very severe COPD (GOLD stage II = moderate, stage III = severe, stage IV = very severe)

- At least two exacerbations treated with antibiotics or systemic steroids in the past year OR at least one exacerbation that resulted in admission to hospital

- Management of COPD already optimal (i.e., long-acting bronchodilators, inhaled steroids, phosphodiesterase 4 inhibitors)

- Compliant with current therapy and using proper inhaler technique Criteria for excluding patients from consideration for azithromycin prophylaxis:

- Prolonged QTc interval on electrocardiography (> $450 \mathrm{~ms}$ ) OR receiving drug therapy that prolongs QTc interval

- Unstable OR uncontrolled cardiovascular disease (congestive heart failure, angina pectoris)

- Hearing impairment documented previously OR apparent on audiometry Note: $\mathrm{COPD}=$ chronic obstructive pulmonary disease, GOLD = Global Initiative for Chronic Obstructive Lung Diseases. 
carry societal implications for increased microbial resistance. Careful selection of patients suitable for long-term macrolide therapy is vital to maximize the benefits and minimize the risks. Our suggested criteria for patient selection, presented in Box 3, are based on the inclusion and exclusion criteria of the studies by Albert and colleagues $^{26}$ and Seemungal and associates, ${ }^{20}$ as well as our own personal experience. Although Albert and colleagues ${ }^{26}$ did not find that other treatments for COPD influenced the potential benefit of azithromycin therapy, we feel it is prudent to use more established therapies for patients with COPD, reserving long-term macrolide treatment for those who continue to suffer exacerbations.

\section{References}

1. Papi A, Bellettato CM, Braccioni F, et al. Infections and airway inflammation in chronic obstructive pulmonary disease severe exacerbations. Am J Respir Crit Care Med 2006;173:1114-21.

2. Sethi $\mathrm{S}$, Wrona $\mathrm{C}$, Eschberger $\mathrm{K}$, et al. Inflammatory profile of new bacterial strain exacerbations of chronic obstructive pulmonary disease. Am J Respir Crit Care Med 2008;177:491-7.

3. Bafadhel M, McKenna S, Terry S, et al. Acute exacerbations of chronic obstructive pulmonary disease: identification of biologic clusters and their biomarkers. Am J Respir Crit Care Med 2011; 184:662-71.

4. Sethi S, Murphy TF. Infection in the pathogenesis and course of chronic obstructive pulmonary disease. N Engl J Med 2008; 359:2355-65

5. Staykova T, Black P, Chacko E, et al. Prophylactic antibiotic therapy for chronic bronchitis. Cochrane Database Syst Rev 2003; (1):CD004105.

6. Sethi S, Maloney J, Grove L, et al. Airway inflammation and bronchial bacterial colonization in chronic obstructive pulmonary disease. Am J Respir Crit Care Med 2006;173:991-8.

7. Johnson DM, Sader HS, Fritsche TR, et al. Susceptibility trends of Haemophilus influenzae and Moraxella catarrhalis against orally administered antimicrobial agents: five-year report from the SENTRY Antimicrobial Surveillance Program. Diagn Microbiol Infect Dis 2003;47:373-6.

8. Jenkins SG, Farrell DJ. Increase in pneumococcus macrolide resistance, United States. Emerg Infect Dis 2009;15:1260-4.

9. Tateda K, Standiford TJ, Pechere JC, et al. Regulatory effects of macrolides on bacterial virulence: potential role as quorumsensing inhibitors. Curr Pharm Des 2004;10:3055-65.

10. Wozniak DJ, Keyser R. Effects of subinhibitory concentrations of macrolide antibiotics on Pseudomonas aeruginosa. Chest 2004;125(2 Suppl):62S-9S

11. Tsai WC, Standiford TJ. Immunomodulatory effects of macrolides in the lung: lessons from in-vitro and in-vivo models. Curr Pharm Des 2004;10:3081-93.

12. Labro MT. Cellular and molecular effects of macrolides on leukocyte function. Curr Pharm Des 2004;10:3067-80.

13. Asgrimsson V, Gudjonsson T, Gudmundsson GH, et al. Novel effects of azithromycin on tight junction proteins in human airway epithelia. Antimicrob Agents Chemother 2006;50:1805-12.

14. Hodge S, Hodge G, Jersmann H, et al. Azithromycin improves macrophage phagocytic function and expression of mannose receptor in chronic obstructive pulmonary disease. Am J Respir Crit Care Med 2008;178:139-48.

15. Berenson CS, Garlipp MA, Grove LJ, et al. Impaired phagocytosis of nontypeable Haemophilus influenzae by human alveolar macrophages in chronic obstructive pulmonary disease. $J$ Infect Dis 2006;194:1375-84

16. Hodge S, Reynolds PN. Low-dose azithromycin improves phagocytosis of bacteria by both alveolar and monocytederived macrophagesin chronic obstructive pulmonary disease subjects. Respirology 2012;17:802-7.

17. Wolter J, Seeney S, Bell S, et al. Effect of long term treatment with azithromycin on disease parameters in cystic fibrosis: a randomised trial. Thorax 2002;57:212-6.

18. Southern KW, Barker PM. Azithromycin for cystic fibrosis. Eur Respir J 2004:24:834-8.

19. Kudoh S, Azuma A, Yamamoto M, et al. Improvement of survival in patients with diffuse panbronchiolitis treated with low-dose erythromycin. Am J Respir Crit Care Med 1998;157:1829-32.

20. Seemungal TAR, Wilkinson TMA, Hurst JR, et al. Long-term erythromycin therapy is associated with decreased chronic obstructive pulmonary disease exacerbations. Am J Respir Crit Care Med 2008;178:1139-47.

21. Suzuki T, Yanai M, Yamaya M, et al. Erythromycin and common cold in COPD. Chest 2001;120:730-3.

22. Rascon-Aguilar IE, Pamer M, Wludyka P, et al. Role of gastroesophageal reflux symptoms in exacerbations of COPD. Chest 2006;130:1096-101.

23. Rohof WO, Bennink RJ, de Ruigh AA, et al. Effect of azithromycin on acid reflux, hiatus hernia and proximal acid pocket in the postprandial period. Gut 2012;61:1670-7.

24. Urbain JL, Vantrappen G, Janssens J, et al. Intravenous erythromycin dramatically accelerates gastric emptying in gastroparesis diabeticorum and normals and abolishes the emptying discrimination between solids and liquids. J Nucl Med 1990;31:1490-3.

25. Banerjee D, Honeybourne D, Khair OA. The effect of oral clarithromycin on bronchial airway inflammation in moderate-tosevere stable COPD: a randomized controlled trial. Treat Respir Med 2004:3:59-65.

26. Albert RK, Connett J, Bailey WC, et al. Azithromycin for prevention of exacerbations of COPD. N Engl J Med 2011;365:689-98.

27. Mick P, Westerberg BD. Sensorineural hearing loss as a probable serious adverse drug reaction associated with low-dose oral azithromycin. J Otolaryngol 2007;36:257-63.

28. Wallace MR, Miller LK, Nguyen MT, et al. Ototoxicity with azithromycin. Lancet 1994;343:241.

29. Ray WA, Murray KT, Hall K, et al. Azithromycin and the risk of cardiovascular death. N Engl J Med 2012;366:1881-90.

30. Svanström H, Pasternak B, Hviid A. Use of azithromycin and death from cardiovascular causes. N Engl J Med 2013;368:1704-12.

31. Desai H, Richter S, Doern G, et al. Antibiotic resistance in sputum isolates of Streptococcus pneumoniae in chronic obstructive pulmonary disease is related to antibiotic exposure. COPD 2010;7:337-44.

32. Hyde TB, Gay K, Stephens DS, et al. Macrolide resistance among invasive Streptococcus pneumoniae isolates. JAMA 2001;286:1857-62.

33. Dagan R, Barkai G, Givon-Lavi N, et al. Seasonality of antibioticresistant Streptococcus pneumoniae that causes acute otitis media: a clue for an antibiotic-restriction policy? J Infect Dis 2008;197: 1094-102.

34. Clement A, Tamalet A, Leroux E, et al. Long term effects of azithromycin in patients with cystic fibrosis: a double blind, placebo controlled trial. Thorax 2006;61:895-902.

Affiliations: Division of Infectious Diseases (Parameswaran) and Division of Pulmonary, Critical Care and Sleep Medicine (Sethi), Department of Medicine, University at Buffalo, The State University of New York, Buffalo, NY; Veterans Affairs Western New York Healthcare System (Parameswaran, Sethi), Buffalo, NY.

Contributors: Both authors were involved in performing the literature search, formulating the manuscript, revising the manuscript for important intellectual content and approving the version submitted for publication. 